\title{
FLOOD INUNDATION ANALYSIS BASED ON UNSTRUCTURED MESHES FOR THE HANOI CENTRAL AREA
}

\author{
Nguyen Tat THANG 1 , Kazuya INOUE ${ }^{2}$, Keiichi TODA ${ }^{3}$ and Kenji KAWAIKE ${ }^{4}$ \\ 1 International Graduate Student, Graduate School of Engineering, Kyoto University (Uji, Kyoto, 611-0011, Japan) \\ ${ }^{2}$ Member of JSCE, Dr. of Eng., Professor, Disaster Prevention Research Institute, Kyoto University (Uji, Kyoto, 611- \\ 0011, Japan) \\ ${ }^{3}$ Member of JSCE, Ph.D., Associate Professor, Disaster Prevention Research Institute, Kyoto University (Uji, Kyoto, \\ 611-0011, Japan) \\ ${ }^{4}$ Member of JSCE, Dr. of Eng., Nagasaki University (1-14, Bunkyo-cho, Nagasaki, 852-8521, Japan)
}

\begin{abstract}
A mathematical model based on unstructured meshes for analyzing 2-D flood inundation is applied to the Hanoi central area. The model application includes three cases: a real heavy rainfall analysis, an assumed exceptionally heavy rainfall analysis and an assumed dike break analysis. The simulation result of the real heavy rainfall analysis shows the general agreement with the observed data. The results of the last two analyses give an overview of flood disasters if they happen to the city. These results show that the applied model could be a useful tool for the city flood control and for the prediction of flood inundation process in any areas of interest.
\end{abstract}

Key Words: Hanoi, flood inundation analysis, heavy rainfall, unstructured meshes, dike break, Red River

\section{INTRODUCTION}

2-D flood inundation analysis for the Hanoi city is a relatively new topic. Recently, most of the flood analyses have been concentrated on 1-D flood simulations in the Red River system. In rainy seasons, some parts of the city are usually flooded by heavy rainfalls. In addition, some big dams, such as the Hoa Binh and Son La hydropower dams, are located in the upstream area of the Red River. As a result, there appears more and more potential of dangerous dike breaks in the downstream areas when sudden extraordinarily big floods or upstream hydropower dam failures occur. In such cases, severe floods are not confined in the approximated 1-D river channels, but rather in 2-D inundation areas. Therefore, a computer model for the 2-D flood inundation analysis is urgently needed to assist the improvement of the city drainage and sewerage system and to predict the inundation process of floods in the area. In addition, the model should have the ability to treat the complicated topography of city area. The 2-D model based on unstructured meshes is therefore a good choice because of the flexibility of the unstructured meshes in describing complicated areas. Here, the model developed by Kawaike et al. (2000)3) is applied.

\section{DESCRIPTION OF THE STUDY AREA}

The study area is the Hanoi central area (Fig. 1). The Red River flows to the South East. A dike system is located along both sides of the river.

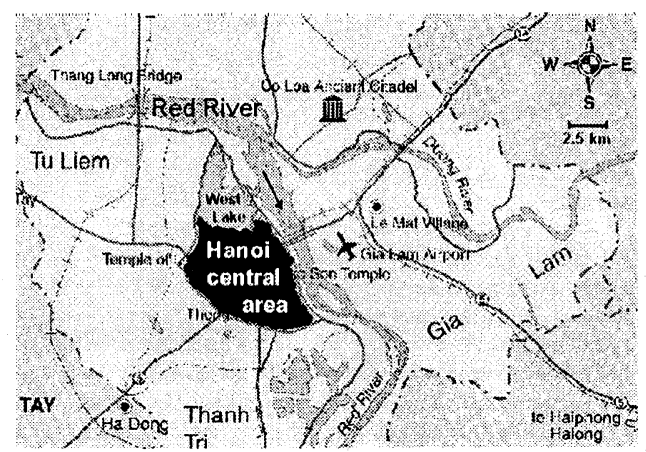

Fig.1 Location of the study area

\section{(1) Characteristics of the area}

The government offices area and the shopping and traditional areas are shown in Fig. 2. There are some small lakes and rivers inside the area (Fig. 5). 


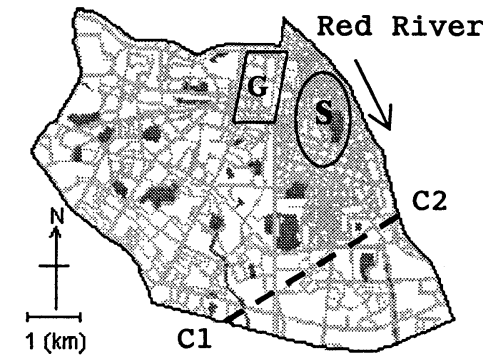

Fig.2 Major areas in the city (G: government offices area, S: shopping and traditional area)

The typical trend of the ground elevation in this area is the inclination in the South-West direction. Especially, the difference between the city ground elevation and the bed elevation of the Red River is not so significant; this is shown in Fig. 3 for one cross section C1-C2 in Fig. 2.

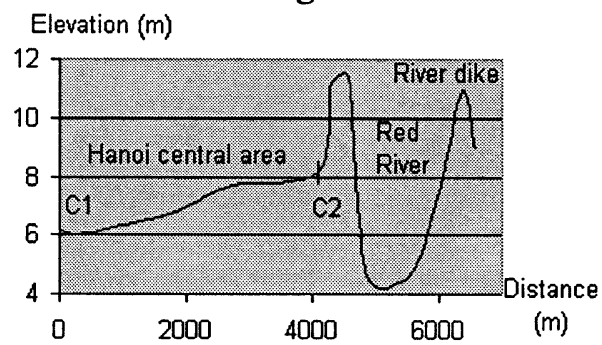

Fig.3 Cross section C1-C2 including its part in the Red River

\section{(2) Flood disasters caused by heavy rainfalls}

In rainy seasons, serious inundation floods caused by heavy rainfalls are quite common in the city (Photo. 1).

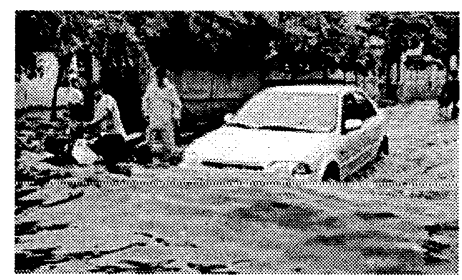

Photo.1 A flood inundation caused by a heavy rainfall in Hanoi

\section{(3) Potential of river dike breaks}

Because the Red River dike is built using soil based on a weak foundation of the river delta, there exists a real potential of dike breaks during exceptionally big floods. In 1971, a historic flood, with the return period of 150 years, occurred in the Red River and caused a real danger of a dike break at Hanoi. The government had to use some upstream flood diversion areas to protect Hanoi.

\section{NUMERICAL TECHNIQUE}

Numerical solutions for 2-D overland flood flows have been developed by Iwasa, Y., Inoue, K. and Mizutori, M. (1980)1) and by Inoue et al. (1994) 2) using the finite difference scheme based on
Cartesian meshes. Kawaike et al. (2000) $)^{3)}$ applied that based on unstructured meshes. In this capital city, streets, lakes, small rivers and residence areas are not located regularly. For such metropolitan area, inundation process should be expressed accurately as much as possible. In most cases, this can be done more exactly and effectively by using unstructured meshes. Then Kawaike's method is applied here.

\section{(1) Basic equations for unsteady 2-D water flow}

The 2-D unsteady flood flow with the consideration of rainfall intensity and drainage capacity can be described by the system of shallow water equations ${ }^{1}$, including:

Continuity equation:

$$
\frac{\partial h}{\partial t}+\frac{\partial M}{\partial x}+\frac{\partial N}{\partial y}=q_{\text {rain }}-q_{\text {drain }}
$$

Momentum equations:

$$
\begin{aligned}
& \frac{\partial M}{\partial t}+\frac{\partial(u M)}{\partial x}+\frac{\partial(v M)}{\partial y}=-g h \frac{\partial H}{\partial x}-\frac{g n^{2} M \sqrt{u^{2}+v^{2}}}{h^{4 / 3}} \\
& \frac{\partial N}{\partial t}+\frac{\partial(u N)}{\partial x}+\frac{\partial(v N)}{\partial y}=-g h \frac{\partial H}{\partial y}-\frac{g n^{2} N \sqrt{u^{2}+v^{2}}}{h^{4 / 3}}
\end{aligned}
$$

where $t$ is time; $u$ and $v$ are $x$ and $y$ components of mean velocity; $h$ is water depth; $M=u h$ and $N=v h ; H=h+z_{b}$ where $z_{b}$ is bed elevation from the reference datum; $g$ is the gravitational acceleration; $n$ is the Manning roughness coefficient; $q_{\text {rain }}$ is rainfall intensity; $q_{\text {drain }}$ is drainage capacity which is approximated to be the depth of water drained away per time unit through drainage and sewerage system.

\section{(2) Solution approach using unstructured meshes}

The method uses the finite difference technique based on unstructured meshes ${ }^{3}$. The study area is divided into convex polygons with arbitrary numbers of sides (Fig. 4). Locations of $M, N$ and $h$ variables in the difference equations are chosen at the center of each side and at the centroid of each mesh, respectively (Fig. 4).

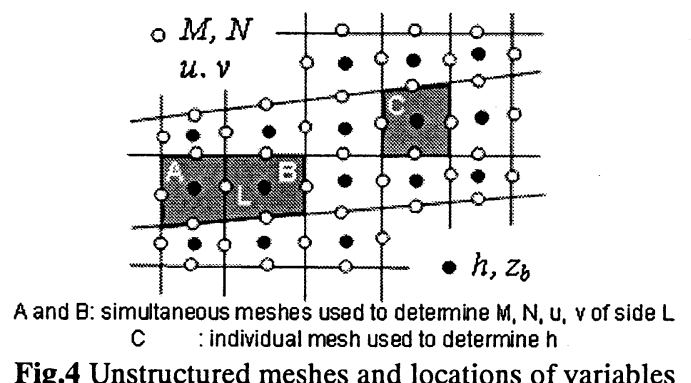

As shown in Fig. 4, $h$ can be determined by using only mesh $C$ and the finite difference form 
for the continuity equation, Eq.(1), is:

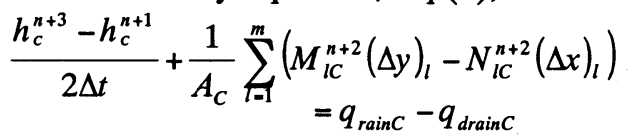

on the other hand, $M, N$ are located on a side, e.g. side $L$, the determination of $M, N$ needs both adjacent meshes $A$ and $B$ of the side $L$ (Fig. 4). The finite difference form for Eq.(2) is:

$$
\begin{aligned}
& \frac{M_{L}^{n+2}-M_{L}^{n}}{2 \Delta t}+m 1+m 2 \\
& =-g \tilde{h}_{L}^{n+1}(\nabla H)_{x}-g n^{2} \frac{\frac{M_{L}^{n+2}+M_{L}^{n}}{2} \sqrt{\left(u_{L}^{n}\right)^{2}+\left(v_{L}^{n}\right)^{2}}}{\left(\tilde{h}_{L}^{n+1}\right)^{4 / 3}} \\
& m 1+m 2=\frac{1}{A_{A+B}} \sum_{i=1}^{m_{A+B}}\left\{\mu_{l}^{n} \hat{M}_{l}^{n}(\Delta y)_{l}-v_{l}^{n} \hat{M}_{l}^{n}(\Delta x)_{l}\right\}
\end{aligned}
$$

The finite difference equation for $N$ is exactly the same form with that of $M$ and is skipped here. $n$ is the step increment; $\Delta t$ is the size of the time step; the subscript $C$ denotes the variables belonging to the mesh $C ; A_{C}$ is the area of the mesh $C ; m$ is the number of sides of the mesh $C$; $M_{l}, N_{l}$ are discharge flux components of side $l$ of the mesh $C ; M_{L}, N_{L}$ are discharge flux components to be determined on the side $L ;(\nabla H)_{x}$ and $(\nabla H)_{y}$ are $x$ - and $y$ - components of the gradient of $H$; $\tilde{h}_{L}$ is the interpolated water depth on the side $L$; $A_{A+B}$ is the sum of the areas of the mesh $A$ and $B$; $m_{A+B}$ is the number of sides of the mesh $A$ and $B$ excluding the side $L ; \hat{M}_{1}$ is $x$ - wise interpolated discharge flux on side $l .(\Delta x)_{l}$ and $(\Delta y)_{l}$ are the differences of the $x$ and $y$ coordinates at both ends of side $l$, respectively. That explicit scheme gives the numerical solution of $M, N, h$ by solving Eq.(5), Eq.(6) and Eq.(4) respectively.

\section{(3) Boundary and initial conditions}

The boundary conditions include those of the followings: dike-break, high wall and free overland flow conditions. As for the dike-break condition, the discharge fluxes of sides of meshes at the break point are calculated by using the known discharge hydrograph of break point. The high wall condition means that, at the physical boundaries, there is no flow flux through these boundaries and the flux is set to be zero. As for the free overland flow condition, the discharge fluxes, at those boundaries where flux could exist, are calculated by using drop type or step down flow formula: $M(N)=(2 / 3)^{3 / 2} h \sqrt{g h}$. In Fig. 6 boundary sections where each type of conditions is applied are shown. B1 B2 is high wall boundary; $\mathrm{B} 2 \sim \mathrm{B} 3$ is free overland flow boundary; $\mathrm{B} 3 \sim \mathrm{B} 1$ is high wall boundary including boundary of assumed dike break point.

As for the initial condition, at the meshes of lakes and small rivers, the water depth is initialized to be the depth of those structures; otherwise it is initialized to be zero.

\section{MODEL APPLICATION}

The mathematical model was applied in three cases of analysis: (1) a simulation of the flood inundation caused by the real heavy rainfall on August $3^{\text {rd }} 2001$ in the Hanoi area, (2) a simulation of an assumed inundation flood caused by the extraordinarily heavy rainfall of the Nagoya city, Japan (Fig. 10), (3) a simulation of a supposed inundation flood caused by an assumed dike break during the historic flood in 1971.

The study area is divided into 5060 unstructured meshes including three categories: the street meshes, the lake and small river meshes and the residence meshes (Fig. 5). Small river, lake and street meshes are treated as meshes with lower ground elevation because there is no bank along rivers in the city.

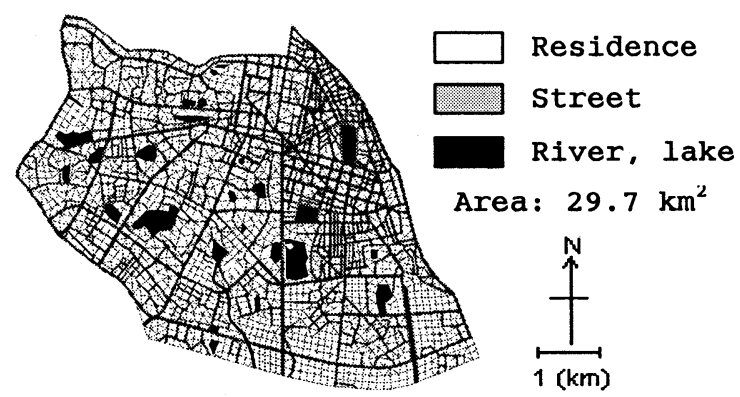

Fig.5 The computation meshes of the study area

The roughness coefficient for street, small river and lake and residence meshes are 0.043, 0.020 and 0.067 , respectively. As for drainage capacity or $q_{d r a i n}$, at present, the drainage and sewerage system of the city is assumed to have capability to decrease $0.01 \mathrm{~m}$ water per hour. Therefore in computations, $q_{\text {drain }}$ at meshes with water depth $h>0.0$ is set to $0.01 \mathrm{~m} / \mathrm{hr}$, otherwise it is set to zero.

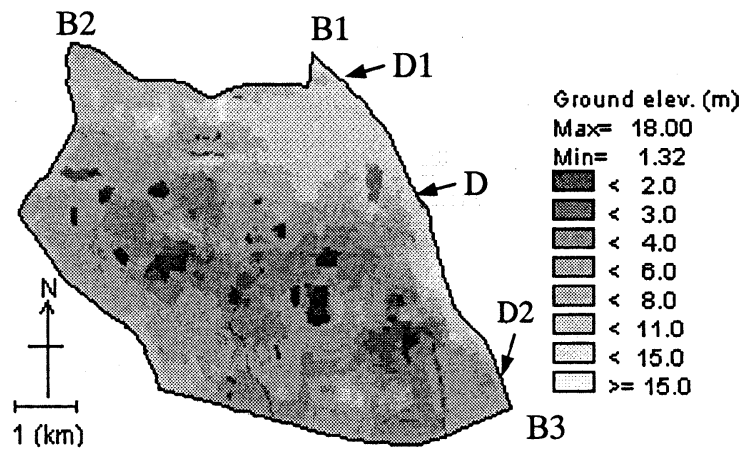

Fig.6 The ground elevation of the study area (D, D1, D2: assumed dike break positions) 


\section{(1) Real heavy rainfall analysis}

The rainfall intensity in this analysis is the recorded historic rainfall (0:00 a.m. to 6:00 a.m.) on August $3^{\text {rd }} 2001$ in the Hanoi area (Fig. 7).

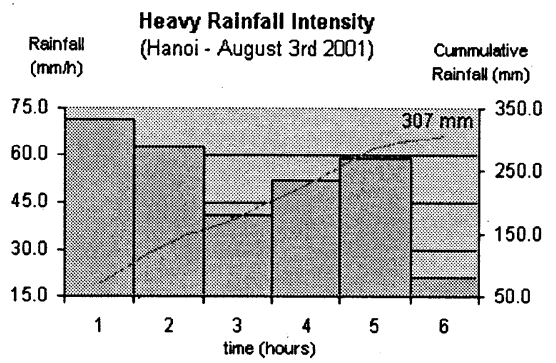

Fig.7 The recorded rainfall on August $3^{\text {rd }} 2001$ at Hanoi

According to the Hanoi Department of Hydrology and Meteorology, the information of some serious flooded areas caused by this rainfall is shown in Table 1 and Fig. 8. The observed data were taken at 9:00 a.m. on August $3^{\text {rd }}$.

Table 1 Observed water depth (averaged in each area)

\begin{tabular}{|l|c|}
\hline \multicolumn{1}{|c|}{ Areas (streets) } & Water depth \\
\hline A (Ba Trieu, Nguyen Du...) & about $1.0 \mathrm{~m}$ \\
\hline B (Nguyen Khuyen, Quoc Tu Giam...) & about $0.6 \mathrm{~m}$ \\
\hline C (Nguyen Chi Thanh) & about $0.3 \mathrm{~m}$ \\
\hline
\end{tabular}

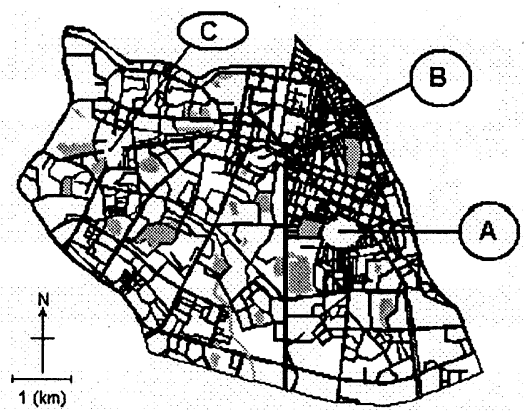

Fig.8 Locations of some serious flooded areas caused by the heavy rainfall on August $3^{\text {rd }} 2001$

As shown in Fig. 9, computed water depths at places A, B, C at 9:00 a.m. agree quite well with the observed water depth. However, water depth at place $\mathrm{C}$ is a little bit smaller than the observed one. The maximum value at that place during the rain is even smaller than $0.3 \mathrm{~m}$. This could be due to the interpolation of ground elevation because the elevation map used does not have high resolution.

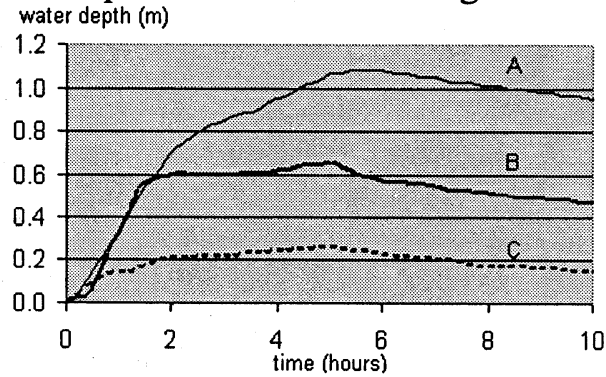

Fig.9 Computed water depth at places A, B, C
(2) Assumed exceptionally heavy rainfall analysis

The observed rainfall intensity of the exceptionally heavy rainfall at the Nagoya city, Japan, is used (Fig. 10). The return period of this type of rainfall in Hanoi is unknown. However due to recent abnormal changes of weather condition, it is believed that heavy rainfalls with the same intensity can occur in the study area.

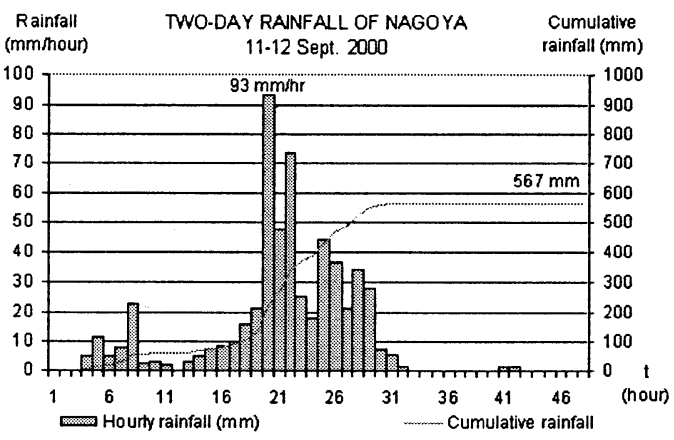

Fig.10 An exceptionally heavy rainfall at the Nagoya city

The computed results are shown in Fig. 11 to Fig. 16. The rain is assumed to start at 0:00 a.m. After $8 \mathrm{hr}$, some areas, not including lake and small river, are flooded with approximate $0.6 \mathrm{~m}$ water depth (Fig. 11).

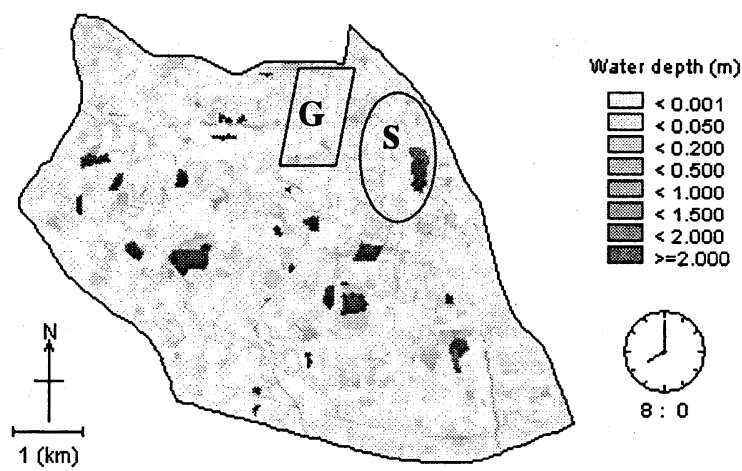

Fig.11 The inundation water depth after $8 \mathrm{hr}$

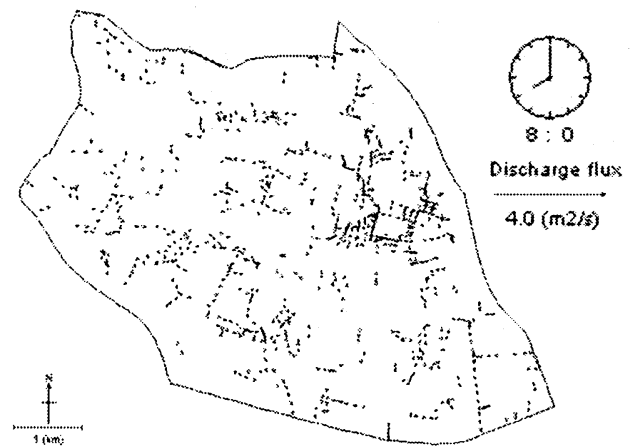

Fig.12 The discharge flux after $8 \mathrm{hr}$

As shown in Fig. 13 and Fig. 14, after $22 \mathrm{hr}$, the water depth reaches its peak value of $1.5 \mathrm{~m}$ in some areas (except lake and small rivers). This peak value remains for about one hour. As shown in Fig. 13, fortunately, almost all the government offices and 
traditional areas are still safe. In most of these areas, water depth is smaller than $0.2 \mathrm{~m}$.

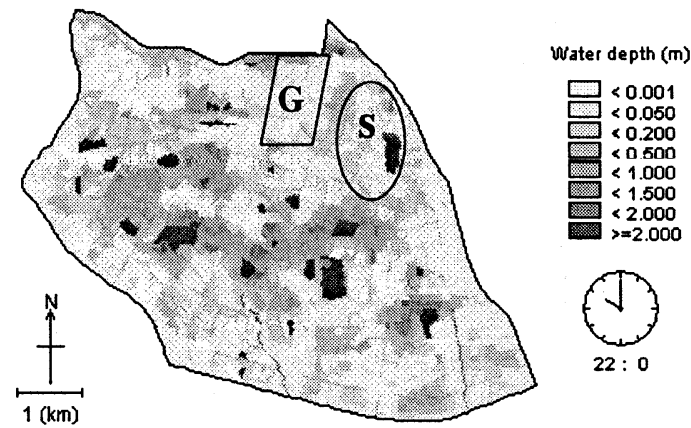

Fig.13 The inundation water depth after $22 \mathrm{~h}$

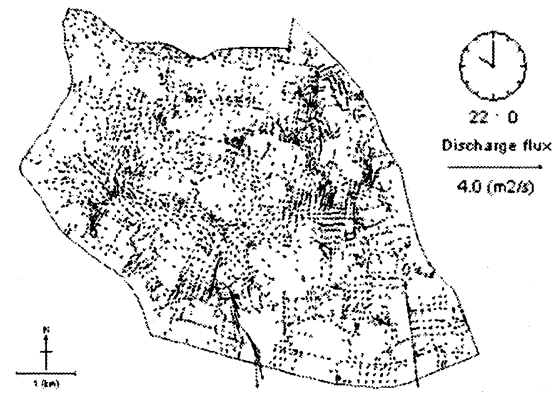

Fig.14 The discharge flux after $22 \mathrm{~h}$

Fig. 15 and Fig. 16 show the inundation process after $35 \mathrm{hr}$. Water depth is still decreasing but very slowly because the present city drainage system is not good. The value of $q_{\text {drain }}$ is supposed to be $0.01 \mathrm{~m} / \mathrm{hr}$ as mentioned before. At that time, the flooded area is no longer too large but the water depth is still high in some low areas. Therefore, measures to evacuate water from low land areas are strongly needed.

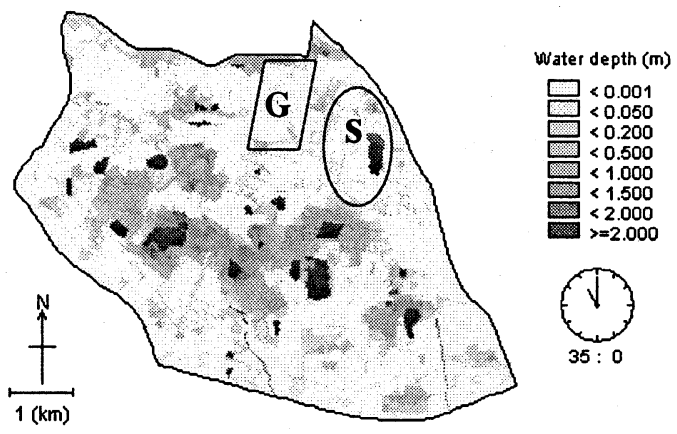

Fig.15 The inundation water depth after $35 \mathrm{hr}$

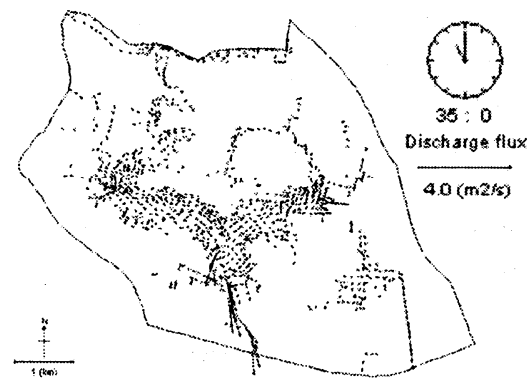

Fig.16 The discharge flux after $35 \mathrm{hr}$
As shown in Fig. 17, the maximum flooded area with $0.5 \mathrm{~m}$ or higher water depth is $18.0 \%$ of the whole study area. After 48 hours, it still remains large, nearly $10 \%$. It is obvious that to cope with such heavy rainfall, the city sewerage and drainage system must be much more improved.

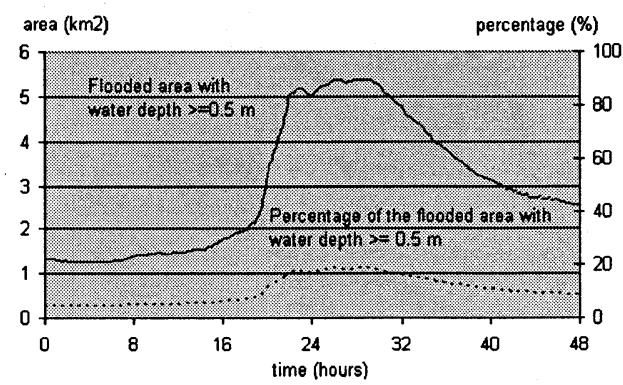

Fig.17 Flooded area with $0.5 \mathrm{~m}$ or higher water depth and its percentage in the whole study area.

\section{(3) Assumed dike break analysis}

Fig. 18 shows the hydrograph observed at Hanoi during the historic flood in August 1971. The real trend of discharge would look like the dotted line which is extrapolated from the observed data, because, at that time, flood water was diverted into the upstream diversion areas to protect Hanoi.

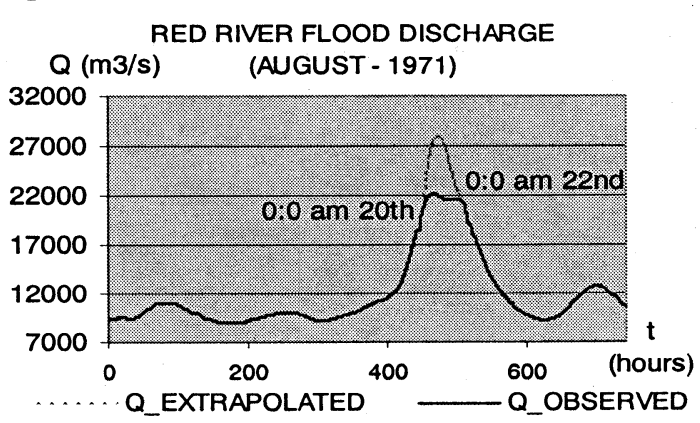

Fig.18 The observed and the extrapolated hydrographs

The difference between the extrapolated and the observed discharge is adopted into the model as the assumed dike break discharge (Fig. 19).

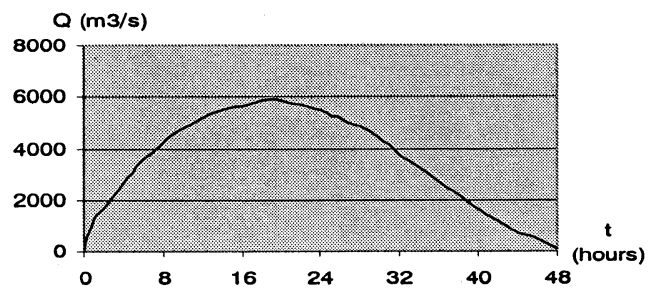

Fig.19 The discharge hydrograph of supposed dike break.

The dike breaks are assumed at three points having lowest ground elevation along Red River dike: D, D1 and D2 (Fig. 6).

Computed result for the assumed dike break at point D is shown. Fig. 20 and Fig. 21 show the inundation process when flood water depth reaches its peak value after $18 \mathrm{hr}$. In Fig. 20, most of the 
central area is severely flooded with greater than 1.0 $\mathrm{m}$ water depth. The major areas, as shown in Fig. 2, are also in very dangerous situation.

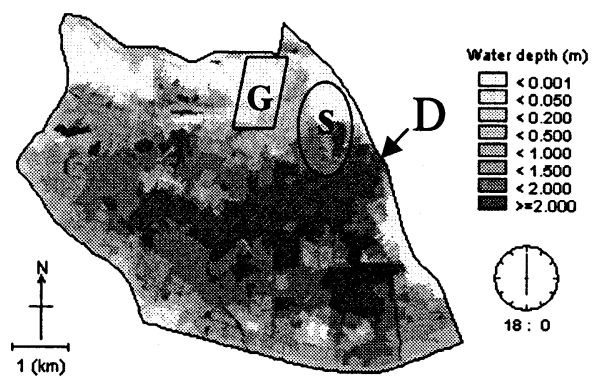

Fig.20 The maximum water depth after $18 \mathrm{hr}$

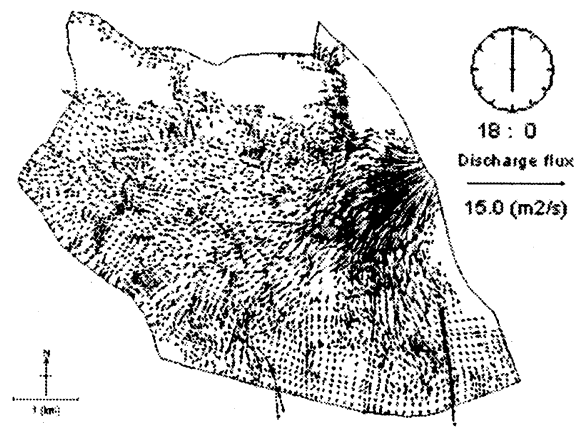

Fig.21 The discharge flux after $18 \mathrm{hr}$

Fig. 22 and Fig. 23 show the flood process after $60 \mathrm{hr}$. At that time the typical water depth, not including river and lake, is about $0.5 \mathrm{~m}$. It means that half a day after the dike break stop, the recovery work could be started.

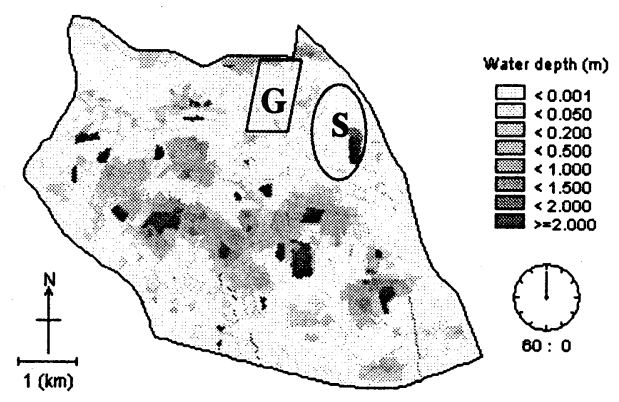

Fig.22 The inundation water depth after $60 \mathrm{hr}$

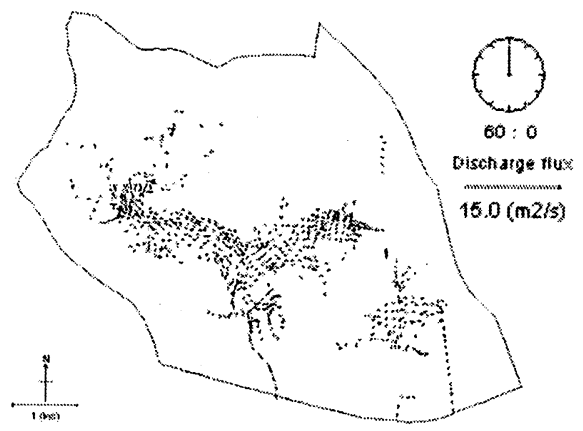

Fig.23 The discharge flux after $60 \mathrm{hr}$

Fig. 24 shows the percentages of flooded area with $0.5 \mathrm{~m}$ or higher water depth for three cases.
The danger level increases if dike break occurs at more upstream points. The maximum percentages of flooded area of three cases of D, D1 and D2 break points are $76.5 \%, 89.7 \%$ and $68.7 \%$, respectively.

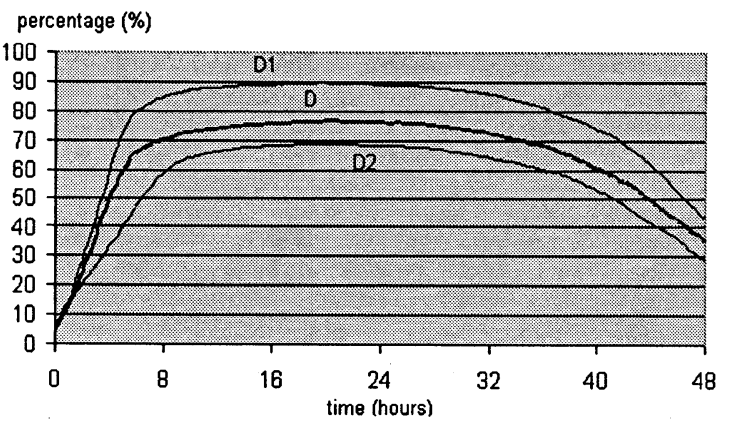

Fig.24 The percentages of flooded area with $0.5 \mathrm{~m}$ or higher water depth of three cases of positions of assumed dike break

\section{CONCLUSIONS AND REMARKS}

The model was successfully applied to the Hanoi central area. The result of the real heavy rainfall analysis roughly agrees with the observed data. The result of an assumed heavy rainfall and an assumed dike break analysis give an overview of the inundation process of floods if they happen to the city. The model could be a useful tool for the city flood control and for the prediction of inundation process in any flood diversion areas. However, to get better result for city areas, it is necessary to incorporate full drainage systems into the model.

\section{ACKNOWLEDGEMENT}

The authors express so deep gratitude to these graduate students: Tokunaga, T., Sagara, R., Nakai, T., Oyagi, R., Nakagawa, Y. and Nishikori, T. at the Civil Engineering Department, Kyoto University, for their very useful helps.

\section{REFERENCES}

1) Iwasa, Y., Inoue, K. and Mizutori, M.: Hydraulic analysis of overland flood flows by means of numerical method, Annual Report of Disaster Prevention Research Institute, Kyoto Univerity, Vol.23 B2, pp.305-317, 1980.

2) Inoue, K., Nakagawa, H. and Toda, K.: Numerical analysis of overland flood flow's by means of one-and two-dimensional models, The $5^{\text {th }}$ JSPS-VCC Seminar On Integrated

Engineering, "Engineering Achievement and Challenges", pp.388-397, 1994.

3) Kawaike, K., Inoue, K. and Toda, K.: Inundation flow modeling in urban area based on the unstructured meshes, Hydrosoft 2000, Hydraulic Engineering Software, VIII, WIT Press, pp.457-466, 2000.

(Received September 30, 2003) 